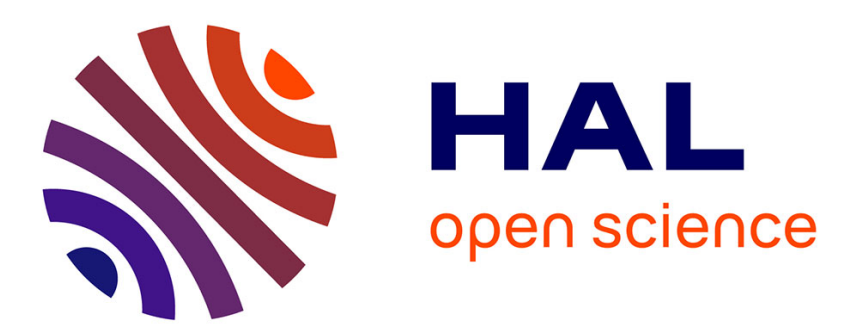

\title{
Answer to the CDC: Validation Must Precede Promotion
}

Samuel Rufat, Eric Tate, Christopher Emrich, Federico Antolini

\section{To cite this version:}

Samuel Rufat, Eric Tate, Christopher Emrich, Federico Antolini. Answer to the CDC: Validation Must Precede Promotion. Annals of the American Association of Geographers, 2020, 111 (4), 10.1080/24694452.2020.1857221 . hal-03146337

\section{HAL Id: hal-03146337 \\ https://hal.science/hal-03146337}

Submitted on 28 Apr 2021

HAL is a multi-disciplinary open access archive for the deposit and dissemination of scientific research documents, whether they are published or not. The documents may come from teaching and research institutions in France or abroad, or from public or private research centers.
L'archive ouverte pluridisciplinaire HAL, est destinée au dépôt et à la diffusion de documents scientifiques de niveau recherche, publiés ou non, émanant des établissements d'enseignement et de recherche français ou étrangers, des laboratoires publics ou privés. 


\section{Answer to the CDC: Validation must Precede Promotion}

Annals of the American Association of Geographers 111(4) doi: 10.1080/24694452.2020.1857221

Samuel Rufat, Department of Geography, CY Cergy Paris University, France, samuel.rufat@u-cergy.fr

Eric Tate, Department of Geography, University of Iowa, eric-tate@uiowa.edu

Christopher T. Emrich, Department of Public Administration, University of Central Florida, Christopher.Emrich@ucf.edu

Federico Antolini, Department of Geography, University of Iowa, federico-antolini@uiowa.edu

\section{Abstract}

We would like to thank the CDC colleagues for their Commentary in what constitutes the first comment on a paper published in the Annals in decades. We view critique as a strength of scientific exploration. The Commentary concludes with as statement agreeing with the findings and conclusions of our paper: "we recognize CDC SVI may not identify the most vulnerable populations in all applications and has not done so in the Rufat et al. study (...) we agree with the authors.”

Key words: hazards, social vulnerability, validation, spatial regression, models

We would like to thank the Centers for Disease Control and Prevention (CDC) colleagues for their commentary in what constitutes the first comment on an article published in the Annals in decades. We view critique as a strength of scientific exploration. The commentary concludes with a statement agreeing with the findings and conclusions of our article: "we recognize CDC SVI may not identify the most vulnerable populations in all applications and has not done so in the Rufat et al. study (...) we agree with the authors." To the authors of the commentary, we previously provided detailed responses to questions via email and in-person, and have also shared geospatial data immediately upon request. We reiterate our invitation to researchers and practitioners to work together in validating and improving social vulnerability models and to draw the appropriate implications in the public interest. Development of conceptually based, yet practically useful social vulnerability measures, has long been our priority and we contend that utility and validity are both of major importance. We are proud to have contributed to opening up this debate: this was one of the explicit objectives of the initial publication. 
As mentioned in the paper, social vulnerability measures, like CDC’s Social Vulnerability Index (SVI), are being used for public policy guidance and resource allocation. For example, Harris County, Texas has been using the SVI as one criterion in prioritizing flood control projects. ${ }^{1}$ It is precisely because the SVI results are regularly promoted (as in the above Commentary) and widely available that it is critical to understand the empirical validity of SVI in comparison to other social vulnerability metrics. Our paper compared the empirical validity of four different models of social vulnerability using outcomes from Hurricane Sandy.

The Commentary begins with a lengthy description of the history and utility of the CDC's SVI. It then embarks on listing some "concerns" regarding our paper before concluding in agreement with our results and conclusions. We will confine our response to the concerns as these provide the most fruitful avenues to hone vulnerability data and models into more useful applications for decision makers. The principal critique of the Commentary appears to be that its authors would have made different choices in parameters and methods. This could be an opportunity to conduct and publish CDC specific validation studies, but the mere existence of plausible alternatives doesn't invalidate our scientific approach or findings. In fact, our paper concludes with a call for researchers to conduct many more validation studies, with variations in parameters such as hazard type, analys is scale, geographic scope, social vulnerability indicators, and outcome measures. Indeed, we assert here that even multiple positive results are never enough to definitively validate one model or another - especially since social vulnerability dynamically manifests differently based on context. Conversely, a single negative empirical result should remain cause for concern - especially in the case of public policy guidance and resource allocation based on such model or data.

Next, we provide more detailed feedback to specific concerns in the commentary. Statements addressing many of the concerns are already present in the article. We refer to those instances in our responses.

\footnotetext{
${ }^{1}$ See for example: Harris County Flood Control District (2019). Prioritization Framework for the Implementation of the 2018 Bond Projects, August 27, 2019. https \%/www.hcfcd.org/Portals/62/Resilience/Bond-Program/PrioritizationFramework/final prioritization-framework-report 20190827.pdf [Retrieved 09.15.2020]
} 


\section{Concern 1 - Data Representation}

a. FEMA Individual Assistance (IA) as an outcome measure. We provided our rationale for IA variables as outcome measures in the paper (in the section "FEMA Outcome Data"), and we stand by it. While IA might not the 'optimal' measure of social vulnerability, there probably isn't one. The arguments made in the Commentary about IA application rates and bureaucracy are reasonable. But that doesn't invalidate IA as a suitable outcome measure. IA does target people with unmet disaster needs, particularly uninsured and underinsured households that have been denied disaster loans. IA focuses on a segment of the population that is both demonstrably affected by disasters and has limited access to resources. This combination of exposure and reduced coping capacity is quintessential social vulnerability. Furthermore, IA data are systematically created upon a Presidential Disaster Declaration, making it instrumental to perform similar assessments across multiple hazard events.

b. Analys is scope. We devoted a subsection of the paper ("Analys is Scope and Scale") to providing rationale for our choices. We stand by them. Regardless, our paper concludes with a call for researchers to conduct many more validation studies with variations in analys is scope and parameters. Ideas suggested in this section of the Commentary are certainly plausible, and we encourage the authors to pursue them in their own research. A broader set of empirical studies is crucial for advancing understanding of the utility and validity of social vulnerability models.

Concern 2 - Analytic Methods

a. We described in several sections of the paper ("Model Comparison", "Model-Level Validation", "Conclusion”) why convergence validity is insufficient to conclude that a measure is accurate. Our own results demonstrate it. Yes, we had also considered that the choice of outc ome measure might pose a larger challenge in validation than the social vulnerability models. The first paragraph of the discussion concludes that: "the variation across models demonstrates that the configuration of a social vulnerability index has a strong influence on its empirical validity. The variation across outcome variables 
demonstrates that disaster outcome measures differ in their efficacy as indicators of human impact."

b. There is no discrepancy in tract area. We modeled social vulnerability for all tracts in all affected counties, as if the assessments were done before the disaster. As described in the methods section ("Social Vulnerability Models") "the models were constructed for all New York and New Jersey census tracts in the affected counties $(N=3,947)$." The convergence ana lyses (Figure 3 and 4$)^{2}$ were performed on all tracts, as could have been done before the disaster. However, the empirical validation was performed after Sandy. As explained in the "Analysis Scope and Scale" section: "73 percent of the census tracts in the disaster-declared counties had no flooding. Accordingly, we set analysis scope to encompass the set of tracts that both intersected the Sandy floodplain and had nonzero FEMA outcomes." The regressions were thus based on a smaller number of tracts, after the disaster, depending on the number of flooded tracts with nonzero outcomes, as detailed in Table 3.

c. Similarly, there is no discrepancy in water depths. Figure 1 is an overview of flood depths across the region. The values in Table 3 represent what we used in the analysis (tracts with nonzero FEMA outcomes). The subsection "Analys is Scope and Scale" describes the places represented by Table 3 .

d. While the Commentary declares that the CDC did not calculate SVI results for nine tracts included in the 1,205-tract extract we sent them, we reiterate that we did construct all models based on the 2008-2012 ACS, not on the CDC products. They found confirmatory results for the SVI to the rounding error.

e. The Commentary asserts that "densely developed areas with high reliance on public transportation, such as Manhattan, should be understood as a social vulnerability" based on 9/11. Our paper analyzes a different disaster manifesting from a different hazard type. While all models examined in our paper include public transportation dependency as factor of social vulnerability, the SVP (not the SVI) is the only one to also include density (see Table 4). The point we make in the paper is that including all variables with equal

\footnotetext{
${ }^{2}$ Please refer to the original paper to find the cited Figures, Sections, and Tables.
} 
weight including rent and transportation dependency tends to represent Manhattan as higher social vulnerability than other neighborhoods with lower socio-economic status. This partly explains the different results from SoVI and the SVI as opposed to the weighted model and SVP. We argue that this might help explain the negative relationship (contrary to the one expected) of SVI results with Sandy outcomes, as evidenced by the Housing and Transportation theme (see Table 10).

f. We respectfully disagree on higher-valued properties. Our outcome variables are agnostic of property value (Table 2) and we also control for exposure (Table 7). The Commentary does not explain the negative association of SVI results with the share of normalized property loss. Furthermore, the SVI results also have negative association with the share of affected renters and the share of damaged homes: the lower the SVI (lower vulnerability), the higher the outcomes have been - all things being equal. In this particular case, it would have been counterproductive to base public policy guidance and public resources' allocation on the SVI results.

\section{Concern 3 - Validation Objectives}

a. This section of the commentary includes an extended description of validity types, concluding with a call for validation testing of social vulnerability in other disaster contexts. This is a central argument in our D iscussion and Conclusion sections, while the second section of the paper ("Model Validation") describes types of validity. Although our analysis found that SVI performed contrary to what is expected and promoted in terms of the Sandy outcome measures, we never stated or suggested that the SVI lacks validity in all contexts.

b. We fully support the aim expressed in the Commentary of conducting and publishing studies of internal and external validity as a prerequisite to releasing and promoting social vulnerability models. We reiterate that this is a central conclusion of our paper.

This type of critical work will only help to illuminate both the successes and sources of concern for future users and the vulnerability science community is dedicated to continuing these types of analyses in relation to many other disaster events. 


\section{Acknowle dgements}

We wish to thank the anonymous reviewers for their time and comments.

\section{References}

Harris County Flood Control District. 2019. Prioritization framework for the implementation of the 2018 bond projects. August 27. Accessed September 15, 2020. https://www.hcfcd.org/Resilience/2018-Bond-Program/Prioritization-Framework

Rufat, S., E. Tate, C. T. Emrich, and F. Antolini. 2019. How valid are social vulnerability models? Annals of the American Association of Geographers 109 (4):1131-53, doi: 10.1080/24694452.2018.1535887. 